\title{
Estimation of Massey Ferguson tractors life and repair distribution functions and required number of repairmen
}

\begin{abstract}
In order to reach suitable and effective performance of farm machines, on time agricultural operations is important. Also, using human resources productively and its productive enhancement needs appropriate planning. In the current study, the life and repair distribution functions of three tractors were estimated, and then, the necessary number of repairmen was determined in such a way that supplies the minimum waiting time to repair in one hand, and maximum human productivity is obtained in the other hand. Three tractors were under the study; i.e. two Massey Ferguson 285 and one Massey Ferguson 399. The tractors working data were gathered for 1100hours. Then, the Monte-Carlo simulation method was applied to simulate tractors working conditions for around 3500hours to have more reliable estimation of life and repair distribution functions. The results showed two functions for life and repair times; i.e. Exponential for life and 2-parameter Weibull for repair. Furthermore, two repairmen should be employed to have minimum waiting time to repair and maximum economic benefits from the view point of useful tractors working hours.
\end{abstract}

Keywords: life distribution function, farm management, maintenance engineering
Volume 7 Issue 6 - 2017

\author{
Ehsan Houshyar, Hossein Rahmanian \\ Department of Biosystems Engineering, Jahrom University, Iran
}

Correspondence: Ehsan Houshyar, Department of Biosystems Engineering, Jahrom University, PO BOX 74I35-I I I, Jahrom, Iran,Email Houshyar.e@Jahrom.ac.ir

Received: July 14, 2017 | Published: November 17, 2017

\section{Introduction}

In order obtain suitable and effective farm machinery performance besides higher crop yield, on time farm machinery field operations are essential. Farm tractors are important machines that used for soil tillage, crop planting and protection. It is even used for harvesting crops in some areas. Thus, any failure in farm tractors influences the series of field operations. Farm managers are usually looking for high reliable farm machineries to complete necessary operation in the pre-determined time Hunt. ${ }^{1}$ However, farm tractors stop due to break downs and it is desired that they repaired on a minimum time and back to farms. Farm machinery costs are divided into two categories, i.e. owning or fixed costs and operating or variable costs Morris. ${ }^{2}$ The cost of farm machinery repair and maintenance can contribute to most of farm machinery operational costs (after fuel) which can be reached to $15-60 \%$ of total crop production costs Mobley. ${ }^{3}$ Having an effective repair and maintenance program, the costs of machinery maintenance and failures will be reduced to an optimum point Lips et al., ${ }^{4}$ by gathering machinery failures data on the farms, the failures distribution function can be estimated well and then some important issues such as machinery reliability and energy failures can be predicted as well Barabadi et al., ${ }^{5}$ Billinton et al. ${ }^{6}$ In addition, the required number of repair-mans can be predicted by simulation of data in such a way that farm machines imposes minimum waiting time for repair. The common life distribution functions for continuous data are Normal, Exponential, Logarithmic and Weibull Haj Shirmohammadi. ${ }^{7}$ Weibull functions with wider applications can be descending, ascending or constant based on the function parameters Bartkute et al. ${ }^{8}$

In a study it has been found that the reliability function of failures data of tractors Massey Ferguson 285 can be estimated by an Exponential function Poozesh et al. ${ }^{9}$ Another study showed that the failures of combine harvester John Deer 955 followed 2-parameter Weibull function Vafaee et al. ${ }^{10}$ Liange $^{11}$ used Exponential function for estimation of farm machinery failures. Rotz ${ }^{12}$ developed a model based on equipment price and operating hours. Testing the model showed that the costs were more realistic when the area worked was considered instead of the operating hours.

After estimation of functions by using available life and repair data, a widely applied method namely Monte-Carlo simulation method was employed to simulate tractors life and repair characteristics for longer time. In other words, Monte-Carlo simulation produces distributions of possible outcome values based on an idea of using randomness to solve problems that might be deterministic in principle Salami. ${ }^{13}$ Monte-Carlo simulation relies on repeated random sampling to obtain numerical results. A simple random sample is a subset of individuals (a sample) chosen from a larger set (a population). Each individual is chosen randomly and entirely by chance while each individual has the same probability of being chosen at any stage during the sampling process, and each subset of $\mathrm{k}$ individuals has the same probability of being chosen for the sample as any other subset of $\mathrm{k}$ individuals. Monte-Carlo simulation then calculates results over and over, each time using a different set of random values from the probability functions. A Monte Carlo simulation could involve thousands or tens of thousands of recalculations before it is complete.

The objective of this study was to estimate two distribution functions for tractors Massey Ferguson 285 (MF285) and 399 (MF399), the first function will estimate life distribution and the second one will be used for estimation of maintenance time. Then, the number of required repair-mans was estimated considering minimum tractors waiting time for repair in one hand, and minimum cost of repair in another hand. The statistical methods were applied to determine distribution function and Monte-Carlo simulation method was used to determine required number of repairmen.

\section{Materials and methods}

This study was conducted in 8 months from spring to autumn 2016 
in Fars province, Iran. The data related to the life of three tractors were gathered. The tractors were MF285 and MF399 having a life of $5100 \mathrm{hr}$ at the time of study. The MF tractors were chosen since this tractor is most common tractor in Iran while MF285 is more available. Thus, we consider the condition of the study when two MF285 and one MF399 are available. The data of tractor repair times was gathered from a local repair center where the data was recorded. The life and repair data of around $1100 \mathrm{hr}$ were gathered representing that when and why each tractor was broken down and how much time was taken to be repaired.

\section{Life and repair distribution functions}

Before estimating life and repair functions, homogeneity of data was analyzed using tendency test. The value of parameter $U$ in this test was calculated as following Hall et al. ${ }^{14}$

$$
U=2 \sum_{t=1}^{k-1} \ln \left(\frac{T_{k}}{T_{t}}\right)
$$

Where $\mathrm{K}$ is the $\mathrm{k}^{\text {th }}$ failure, $\mathrm{T}_{\mathrm{k}}$ is sum of tractor working hours, $\mathrm{T}_{t}$ is life of tractor. If the calculated parameter $\mathrm{U}$ is higher than the $U$ from Chi square table (probability level $=0.95$ and degree of freedom $=2(n-1))$, the data is homogeneous.

Then, to find the best function, the fitting curve test using MATLAB was employed. Different fitting functions including Exponential, Normal, Weibull and Poisson were examined to find the best fitted model considering $\mathrm{R}^{2}$ and RMSE. The examined Exponential and 2-parameter Weibull functions are given here as an example:

$$
\begin{aligned}
& f(t)=\lambda e^{-\lambda t} \\
& g(t)=\frac{\beta}{\alpha}\left(\frac{t}{\alpha}\right)^{\beta-1} e^{-\left(\frac{t}{\alpha}\right)^{\beta}}
\end{aligned}
$$

Where $\lambda$ istherateoffailures; tis thelifetimeorrepairtime; $\boldsymbol{\alpha}$ and $\boldsymbol{\beta}$ arethe Properties of distribution function.

\section{Using Monte-Carlo simulation by life and repair cumulative functions}

As stated before, the data related to the $1100 \mathrm{hr}$ tractors working hour was gathered. Cumulative functions were used to simulate life and repair times of tractors in longer working hours. Thus, after estimation of life and repair distribution functions, corresponding cumulative functions were determined. For instance, the cumulative form for Exponential and 2-parameter Weibull functions are as following:

$$
\begin{aligned}
& F(t)=1-e^{-\lambda t} \\
& \mathrm{G}(\mathrm{t})=1-\mathrm{e}^{-\mathrm{t}^{\beta}}
\end{aligned}
$$

Where $t$ is the life time or repair time; $\lambda$ is the rate of failures; $t$ is the life time or repair time; $\boldsymbol{\beta}$ is the properties of distribution function.

As the next step, using Monte-Carlo simulation and MATLAB software, the performance of tractors were simulated for 3500hours while it was determined that for any life span, how much time was spent for repair during all this 3500 hours. The required number of repairmen to repair these three tractors were determined in such a way that minimum waiting time to repair and minimum cost of repair were obtained. To meet this purpose, the result of three tractors simulations were drawn simultaneously in Excel software assuming the existence of one, two and three repairmen to clarify repair times besides waiting time to repair in a graph. Finally, the optimum number of repairman was determined with regard to the cost of repair and timeliness cost of tractors. The cost of repair was considered as high as an experienced repairman (above 5years experience) will be hired.

\section{Results and discussion}

\section{Fitting model}

The parameter $U$ of tendency test was higher than that of chisquare for all the tractors meaning that the data related to the life and repair times were homogeneous Hall et al. ${ }^{14}$ The fitting tests revealed that the best function for tractors' life and repair were Exponential and 2-parameter Weibull, respectively. The fitted Exponential function of tractor T1 has been shown in Figure 1. The parameter $\lambda$ for tractors $\mathrm{T} 1, \mathrm{~T} 2$ and T3 were $0.021,0.017$ and 0.023 , respectively. Accordingly, the life function of tractors has been given in Table 1. The parameter $\alpha$ and $\beta$ and the predicted 2-parameter Weibull functions of tractors $\mathrm{T} 1, \mathrm{~T} 2$ and T3 has been shown in Table 2. The magnitude of $\beta$ for $\mathrm{T} 3$ shows that the tractor is near to the end of its economic life or the frequency of repairs are increased Najafi et al., ${ }^{15}$ In other words, tractor $\mathrm{T} 3$ need more repair than tractors $\mathrm{T} 1$ and $\mathrm{T} 2$. After the prediction of distribution functions, the cumulative functions were estimated. The cumulative function of tractor $\mathrm{T} 1$, for instance, is as following: Cumulative Exponential function

$$
F(t)=1-e^{(-0.021 t)}
$$

The Monte-Carlo simulation was applied to simulate life and repair times of tractors for 3500 hours. Some part of the results has been shown in Table 3. For instance, the first random data from the simulation of $\mathrm{T} 1$ was 0.48 and the corresponding life was $31.3 \mathrm{hr}$, and for the repair simulation, the first random data was 0.96 and the corresponding repair time was $4.75 \mathrm{hr}$. the data for tractors $\mathrm{T} 2$ and $\mathrm{T} 3$ are also given as well.

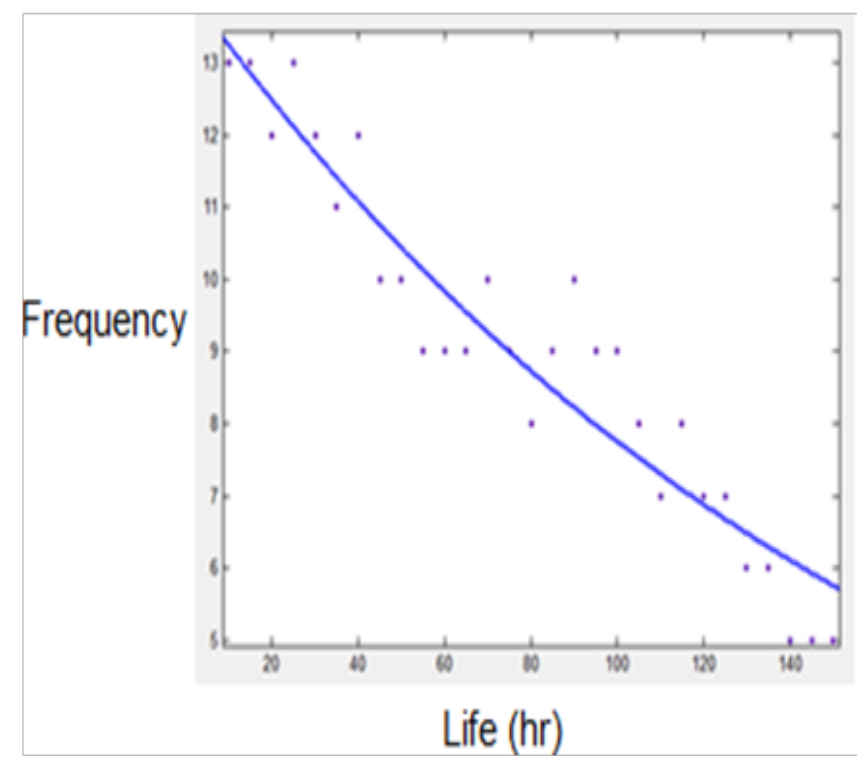

Figure I The fitted Exponential function of tractor TI life. 
Table I Predicted life distribution functions for Massey Ferguson tractors $\mathrm{TI}, \mathrm{T} 2$ and T3

\begin{tabular}{|c|c|c|c|}
\hline Tractor type & $\begin{array}{l}\text { Life distribution function } \\
f(t)\end{array}$ & $\mathbf{R 2}$ & RMSE \\
\hline TI & $0.02 \mathrm{le}-0.02 \mathrm{l} t$ & 0.87 & 0.0018 \\
\hline $\mathrm{T} 2$ & $0.017 e-0.017 t$ & 0.89 & 0.001 \\
\hline T3 & $0.023 e-0.023 t$ & 0.87 & 0.0019 \\
\hline
\end{tabular}

\section{The graph of tractors working hours}

The data of simulation was used to draw the graph of tractors working hours besides times to repairs. ${ }^{16}$ The drawing was completed in three mode: 1- employing only one repairman, 2- employing two repairmen and 3- employing three repairmen. The priority of repairs was from $\mathrm{T} 1$ to $\mathrm{T} 3$ meaning that when two tractors need to be repaired, the first tractor for repairing is $\mathrm{T} 1$, then $\mathrm{T} 2$ and finally T3. Another assumption is that each repairman works independently Figure 2 shows the simulation of three tractors for $500 \mathrm{hr}$ employing one repairman. Although the simulation was completed for $3500 \mathrm{hr}$, the graph has been shown for $500 \mathrm{hr}$ due to limitation in space. Figure 3 shows the simulation of three tractors employing two repairmen (Figure 2) reveal that after $30 \mathrm{hr}$ working time, both the tractors $\mathrm{T} 1$ and $\mathrm{T} 3$ required to be repaired. Because of predetermined priority, tractor $\mathrm{T} 1$ is repaired first and meanwhile tractor $\mathrm{T} 3$ imposed $5 \mathrm{hr}$ waiting time. Then tractor T3 has been repaired. When we have two repairmen (Figure 3), two tractors (T1 and $\mathrm{T} 3$ ) have been repaired simultaneously and the waiting time of tractor T3 has been omitted.

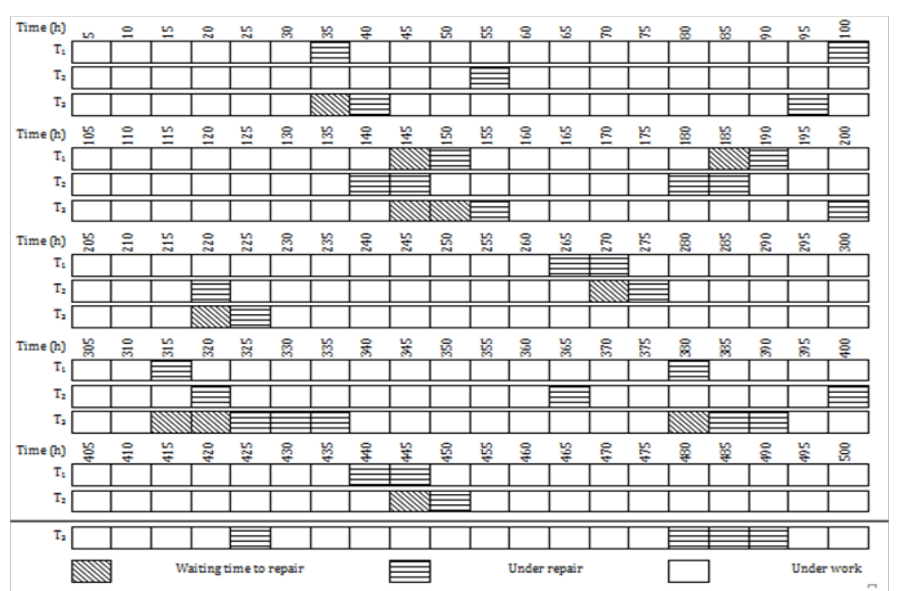

Figure $\mathbf{2}$ The graph of three tractors working hours when one repairman is employed.

Comparing (Figure 2) (Figure 3) reveal that waiting time is reduced when two repairmen are employed. The result of $3500 \mathrm{hr}$ simulation is tabulated in Table 4. The outputs clarify that in all the simulation modes, i.e. with one repairman, two and three repairmen, tractor T3 had the highest repairing time and waiting time to repair. The below calculations were done by using data given in Table 4 to investigate how many repairman is required in the repair and maintenance center in order to repair tractors with minimum waiting time and minimum cost.

If one repairman is employed: In this condition, the repairman will be at the work for $3500 \mathrm{hr}$, but there will be $1397.1 \mathrm{hr}$ down time (waiting time+time to repair). The sum of hours that the three tractors are repaired is $1025.6 \mathrm{hr}$. The cost of repairing is given in Table 5 .

If two repairmen are employed: When there are two repairmen at the work, they will at work for $7000 \mathrm{hr}$ (Table 6). Accordingly, there will be $1106.7 \mathrm{hr}$ down time (waiting time+time to repair).

If three repairmen are employed: Three repairmen are available for a total of $10500 \mathrm{hr}$ while they work on the tractors for 1025.6 and the total down time (waiting time + time to repair) is 1025.6 (Table 7).

The result of (Tables 5-7) clarifies that the two repairmen should be employed to have minimum wait time to repair and minimum cost of repair. When there are two repairmen, the amount of waiting time to repair is reduced of $300 \mathrm{hr}$, i.e. from $370 \mathrm{hr}$ to $70 \mathrm{hr}$. The calculations revealed that the waiting time reduced even more (reach to zero) when there are three repairmen, but the cost of each tractors working hour is increased three times. Accordingly, for the current status, it is not reasonable to employ more than two repairmen.

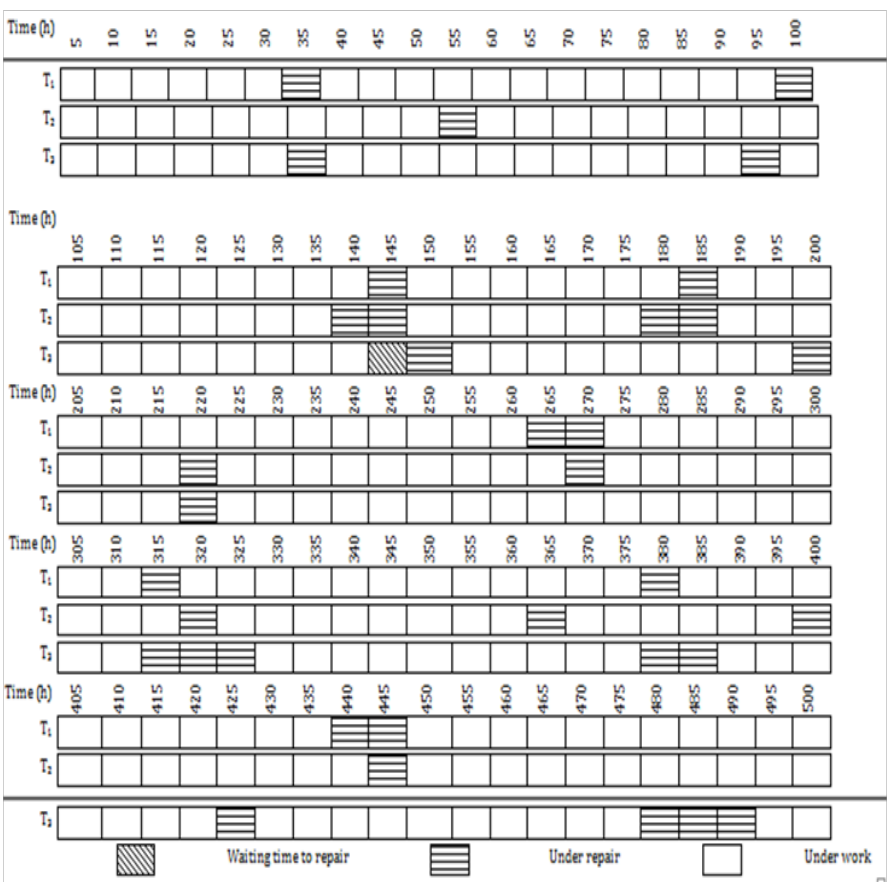

Figure $\mathbf{3}$ The graph of three tractors working hours when two repairmen are employed.

Table 2 Predicted repair function for Massey Ferguson tractors TI,T2 and T3

\section{Tractor type Parameter ParameterRepair function $\mathrm{g}(\mathrm{t})$}

$\begin{array}{llll}\text { TI } & 7.28 & 0.78 & \begin{array}{l}(0.78 / 7.28) \cdot t 0.78-\mathrm{I} . \\ \mathrm{e}-t(0.78 / 7.28)\end{array}\end{array}$

$\begin{array}{cccl}\text { T2 } & 6.31 & 0.63 & \begin{array}{l}(0.63 / 6.31) . t 0.78-1 . \\ e-t(0.63 / 6.31)\end{array} \\ & & & \\ \text { T3 } & 5.83 & 0.55 & \begin{array}{l}(0.55 / 5.83) . t 0.78-1 . \\ \mathrm{e}-t(0.55 / 5.83)\end{array}\end{array}$


Table 3 Life time and repair time of Massey Ferguson tractors by Monte-Carlo simulation method

\begin{tabular}{|c|c|c|c|c|c|c|c|c|c|c|}
\hline \multicolumn{4}{|c|}{ Tractor TI (MF285) } & \multicolumn{4}{|c|}{ Tractor T2(MF285) } & \multicolumn{3}{|c|}{ Tractor T3(MF399) } \\
\hline $\begin{array}{l}\text { Random } \\
\text { Number }\end{array}$ & Life (h) & $\begin{array}{l}\text { Random } \\
\text { number }\end{array}$ & $\begin{array}{l}\text { Maintenance } \\
\text { Time }\end{array}$ & $\begin{array}{l}\text { Random } \\
\text { number }\end{array}$ & Life (h) & $\begin{array}{l}\text { Random } \\
\text { number }\end{array}$ & $\begin{array}{l}\text { Maintenance } \\
\text { Time }\end{array}$ & $\begin{array}{l}\text { Random } \\
\text { number }\end{array}$ & Life (h) & $\begin{array}{l}\text { Random } \\
\text { Number }\end{array}$ \\
\hline 0.96 & 31.3 & 0.48 & 4.75 & 0.62 & 53.41 & 0.94 & 4.54 & 0.81 & 34.32 & 0.56 \\
\hline 0.98 & 60.33 & 0.72 & 5.72 & 0.77 & 82.54 & 0.88 & 4.66 & 0.79 & 53.22 & 0.7 \\
\hline 0.71 & 43.91 & 0.64 & 3.15 & 0.38 & 27.62 & 0.9 & 5.32 & 0.92 & 45.44 & 0.61 \\
\hline
\end{tabular}

Table 4 Sum of working, waiting and repair times for three tractors by Monte- Carlo simulation method

\begin{tabular}{llllll}
\hline $\begin{array}{l}\text { Number of maintenance } \\
\text { labor }\end{array}$ & Time (h) & \multicolumn{2}{c}{ Tractor T I Tractor T2 } & Tractor T3 Sum \\
\hline \multirow{2}{*}{$\begin{array}{lllll}\text { One Repairman } \\
\text { working time }\end{array}$} & 3169.5 & 3109.2 & 2824.2 & 9102.9 \\
& Waiting time & 55.3 & 80.7 & 235.5 & 371.5 \\
& repair time & 275.2 & 310.1 & 440.3 & 1025.6 \\
& Sum & 3500 & 3500 & 3500 & 10500 \\
& working time & 3209.5 & 3164.6 & 3019.2 & 9393.3 \\
Two Repairmen & Waiting time & 15.3 & 25.3 & 40.5 & 81.1 \\
& repair time & 275.2 & 310.1 & 440.3 & 1025.6 \\
& Sum & 3500 & 3500 & 3500 & 10500 \\
& working time & 3224.8 & 3189.9 & 3059.7 & 9774.4 \\
Three Repairmen & Waiting time & 0 & 0 & 0 & 0 \\
& repair time & 275.2 & 310.1 & 440.3 & 1025.6 \\
\hline
\end{tabular}

Table 5 The cost of repairing when one repairman is employed

\begin{tabular}{ll}
\hline Costs & \\
\hline $350,000 \mathrm{Rial} / \mathrm{hr} \times 1,397 . \mathrm{lhr}=488,985,000 \mathrm{Rial}$ & Down time \\
$70,000 \mathrm{Rial} / \mathrm{hr} \times 1,025.6 \mathrm{hr}=71,792,000 \mathrm{Rial}$ & Repair time \\
I5,000Rial $/ \mathrm{hr} \times 3,500 \mathrm{hr}=52,500,000 \mathrm{Rial}$ & Wage \\
$613,277,000 \mathrm{Rial}$ & Sum \\
$610,400,000 \div 9,102.9=6,7371.6 \mathrm{IRial}$ & $\begin{array}{l}\text { The cost of each useful } \\
\text { working hour }\end{array}$ \\
\hline
\end{tabular}

Table 6 The cost of repairing when two repairmen are employed

\begin{tabular}{|c|c|}
\hline \multicolumn{2}{|l|}{ Costs } \\
\hline $350,000 \mathrm{Rial} / \mathrm{hr} \times 1,106.7 \mathrm{hr}=387,345,000 \mathrm{Riz}$ & Down time \\
\hline 70,000Rial $/ \mathrm{hr} \times 1,025.6 \mathrm{hr}=71,792,000 \mathrm{Rial}$ & Repair time \\
\hline I5,000Rial $/ \mathrm{hr} \times 7,000 \mathrm{hr}=105,000,000 \mathrm{Rial}$ & Wage \\
\hline 564, I37,000Rial & Sum \\
\hline $564,137,000 \div 9,393.3=60057.38 \mathrm{Rial}$ & $\begin{array}{l}\text { The cost of each useful } \\
\text { working hour }\end{array}$ \\
\hline
\end{tabular}

Table 7 The cost of repairing when three repairmen are employed

\begin{tabular}{ll}
\hline Costs & \\
\hline $350,000 \mathrm{Rial} / \mathrm{hr} \times 1,025.6 \mathrm{hr}=358,960,000 \mathrm{Rial}$ & Down time \\
$70,000 \mathrm{Rial} / \mathrm{hr} \times|, 025.6 \mathrm{hr}=7|, 792,000 \mathrm{Rial}$ & Repair time \\
$15,000 \mathrm{Rial} / \mathrm{hr} \times 10,500 \mathrm{hr}=1,575,000,000 \mathrm{Rial}$ & Wage \\
$2,005,752,000 \mathrm{Rial}$ & Sum \\
$564,137,000 \div 9,474.4=2 \mid 1,702.27 \mathrm{Rial}$ & $\begin{array}{l}\text { The cost of each useful } \\
\text { working hour }\end{array}$ \\
&
\end{tabular}

\section{Conclusion}

Most studies have focused on the estimation of tractors repair and maintenance costs, not estimation of required repairmen for tractors to minimize tractors down time. This is the first study on the investigation of required number of repairmen for Massey Ferguson tractors in Iran in order to minimize costs of repair and waiting time to repairs. The results showed that the best function for life and repair of tractors were Exponential and 2-parameter Weibull distribution function, respectively.

Monte-Carlo simulation suggested that two repairmen should be employed if minimum cost besides minimum waiting time is critical. Although only the calculations related to the costs have been shown here, the reduction on the waiting times lead to one time farm 
operations which in turn increase crop yield which is not described more here. More investigation on this issue is suggested for future studies. Our observations revealed that around $80 \%$ of farmers are more satisfied with tractor MF285 than MF399. Seemingly, one of the reasons is that farmers are not so practically familiar with the new tractor MF399 and cannot work with it suitably.

Especially, some of regular daily and weekly services are important to mitigate emergency repairs and maintenances. The fitting of load with tractor power is also effective to reduce unwanted repairs. Currently, most farmers do not pass training periods in tractor regular services and work based on their experience. It is estimated that increasing farmers' knowledge especially to use MF399 (driving, regular services) is essential for $60 \%$ of farmers to improve machinery use efficiency.

\section{Acknowledgements}

None.

\section{Conflict of interest}

The author declares no conflict of interest.

\section{References}

1. Hunt D. Farm power and machinery management. USA: Iowa State Press; 2001. p. 1-368.

2. Morris J. Estimation of tractor repair and maintenance costs. Journal of Agricultural Engineering Research. 1988;41(3):191-200.

3. Mobley RK. An introduction to predictive maintenance. USA: Elsevier science press; 2002. p. 1-438.

4. Lips M, Burose F. Repair and maintenance costs for agricultural machines. Int Journal of Agric Management. 2012;1(3):40-46.

5. Barabadi J, Kumar U. Reliability analysis of mining equipment:a case study of a crushing plant at Jajarm Bauxite mine in Iran. Reliability Engineering and System Safety. 2008;93(4):647-653.
6. Billinton R, Allan RN. Reliability evaluation of engineering systems: concepts and techniques. Translated by M. Rezaeeian. Iran: Amir Kabir University; 2012. p. 1-496.

7. Haj Shirmohammadi A. Industrial maintenance and planning and control. 10th ed. Iran: Arkan danesh Press; 2005. p. 1- 516.

8. Bartkute V, Sakalauskas L. The method of three-parameter weibull distribution estimation. Acta et Commendations Universitatis Tartuensis de Mathematica. 2008;12:65-78.

9. Poozesh M, Mohtasabi SS, Ahmadi H. Determination of reliability function for MF 285 tractors at Daabal Khozaei Agro-industry in Khouzestan. 6th Agricultural Machinery and Mechanization Conference. Iran; 2010

10. Vafaee MR, Mashhadi Meighani H, Almasi M, et al. Choosing the best method of estimating reliability parameter for grain harvesting machines in Markazi province, Iran. Agroecology Journal. 2009;5(12):143-151.

11. Liange T. A dynamic programming Markov chain approach to farm machinery preventive maintenance problems. Department of Biological and Agricultural Engineering. Raleigh, North Carolina; 1967.

12. Rotz CA. A standard model for repair costs of agricultural machinery. Applied Engineering in Agriculture. 1987;3(1):3-9.

13. Salami AB. A review of the Monte Carlo simulation method. Economics Research. 2003;3(8):117-138.

14. Hall RA, Daneshmend LK. Reliability modeling of surface mining equipment: data gathering and analysis methodologies. International Journal of Surface Mining and Reclamation and Environment. 2010;17(3):139-155.

15. Najafi P, Assodar MA, Marzban A, et al. Reliability evaluation and analysis of sugarcane 7000 series harvesters in sugarcane harvesting. Journal of Agricultural Machinery. 2015;5(2):446- 455.

16. Meeker WQ, Escobar L. Statistical methods for reliability data. USA: John Wiley and sons; 1998. p. 1-680. 